\title{
Isaacs syndrome: the frontier of neurology, psychiatry, immunology and cancer
}

\author{
Susanna B Park, ${ }^{1}$ Rick Thurbon, ${ }^{2}$ Matthew C Kiernan ${ }^{3,4}$
}

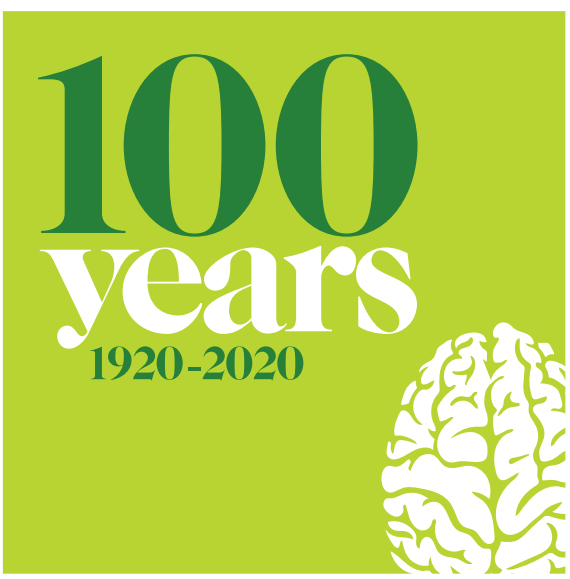

Evolution of Isaacs syndrome from case studies that described continuous ectopic activity through to an understanding as a multisystem autoimmune condition

Six decades ago, Dr Hyam Isaacs reported a new clinical syndrome in the Journal of Neurology, Neurosurgery and Psychiatry. ${ }^{1}$ Isaacs used the term 'syndrome of continuous muscle-fibre activity' or the more descriptive 'armadillo disease' for the condition which now has become known as Isaacs syndrome or acquired autoimmune neuromyotonia. In his landmark series, Isaacs described a phenotype of progressive muscle stiffness, with widespread fasciculation leading to weakness. A key finding was continuous muscle activity on electromyography, occurring at rest and unaffected by local nerve blockade. The original report also detailed a number of unsuccessful treatment approaches, as well as an astonishing improvement

${ }^{1}$ Brain and Mind Centre, Faculty of Medicine and Health, University of Sydney, Sydney, New South Wales, Australia

${ }^{2}$ Patient Editorial Board, Journal of Neurology, Neurosurgery and Psychiatry, Tavistock Square, London, UK

${ }^{3}$ Bushell Chair of Neurology, Brain and Mind Centre, University of Sydney, Sydney, New South Wales, Australia

${ }^{4}$ Neurology, Royal Prince Alfred Hospital, Camperdown, New South Wales, Australia

Correspondence to Dr Susanna B Park, Sydney Medical School, The University of Sydney, Brain and Mind Centre, Camperdown, NSW 2050, Australia; susanna.park@sydney.edu.au
A syndrome of continuous muscle-fibre activity

Authors: Isaacs $\mathrm{H}$

Year published: 1961

Number of times cited: 480

produced by sodium diphenyl hydantoinate (phenytoin) treatment.

Over the past 60 years, while we have learnt much more about the pathophysiology of Isaacs syndrome, there are still many elements that remain unresolved. A critical factor in understanding the Isaacs jigsaw puzzle came with the identification of the autoimmune basis for the disorder by the group led by John Newsom-Davis and Angela Vincent. ${ }^{2}$ The demonstration of pathogenic immunoglobulin G (IgG) autoantibodies in a patient with severe Isaacs syndrome refractory to treatment, and the successful use of plasma exchange to ameliorate symptoms, ${ }^{2}$ highlighted the role of the immune system in the syndrome and provided another avenue of treatment approaches.

Presently, autoantibodies are identified in a significant proportion $(45-50 \%)$ of Isaacs syndrome patients. ${ }^{3}{ }^{4}$ These were initially considered to be antibodies against voltage-gated potassium channels (VGKC), but in the past 10 years the molecular identity of these autoantibodies has been further clarified, with targets revealed to be VGKC-complex proteins including contactin associated protein 2 (CASPR2) and leucine-rich glioma inactivated 1 (LGI1). ${ }^{56}$ The molecular identification of these antibodies has revealed a spectrum of overlapping disorders from Isaacs syndrome, through to Morvan's syndrome and limbic encephalitis. ${ }^{78}$ However, the lack of specific antibody targets in the remaining patients suggests that there are likely to be additional autoantibody targets yet to be discovered.

In addition to the classical muscle symptoms of Isaacs syndrome, there is a spectrum of autonomic and central nervous system (CNS) involvement that link Isaacs syndrome to other autoimmune disorders. Sensory symptoms including paraesthesia and pain and autonomic disturbance including excessive sweating, tachycardia or diarrhoea are reported by almost half of patients. ${ }^{3}$ CNS symptoms are also prominently reported including insomnia, personality and mood changes, anxiety and depression. ${ }^{3}{ }^{4}$ There is no specific association of autoantibody type with clinical symptoms-while LGI1 antibodies are primarily associated with limbic encephalitis and CNS involvement, 31\% of patients display peripheral involvement including hyperexcitability or neuropathic pain in $>20 \%$. ${ }^{9}$ Similarly, CASPR2 antibodies are associated with both CNS and peripheral-predominant clinical presentations, ${ }^{9}$ and associated with neuromyotonia in $<40 \%$ of cases. ${ }^{10}$ Further clinical and molecular phenotyping of large-scale cohorts will be necessary to determine specific associations with neuromyotonia across syndromes.

Underlying the immune basis of Isaacs syndrome there is a prominent association with cancer, with $21-25 \%$ of Isaacs syndrome patients diagnosed with recent tumours, ${ }^{34}$ highlighting the need to screen carefully for malignancy. In particular, CASPR2 antibodies are associated with thymoma in $20 \%$ of cases. ${ }^{10}$ The association with cancer suggests that Isaacs syndrome can develop through paraneoplastic mechanisms, with tumourassociated antigens triggering an autoimmune response via cross-reacting antibodies with nerve related epitopes.

In terms of understanding the clinical hallmark of Isaacs syndrome, namely continuous muscle activity, the site of origin for this spontaneous activity remains to be determined. The typical patterns of ectopic activity (figure 1) do not seem to be caused by a generalised disturbance of motor axon membrane excitability. ${ }^{8} 1112$ Most likely, the activity is generated focally, perhaps at the motor nerve terminal which is relatively unprotected by the blood-nerve barrier, making it vulnerable to autoantibody attack. A proximal or central generator of ectopic activity seems less likely, particularly in the context of normal corticomotorneuronal integrity as established in acquired 


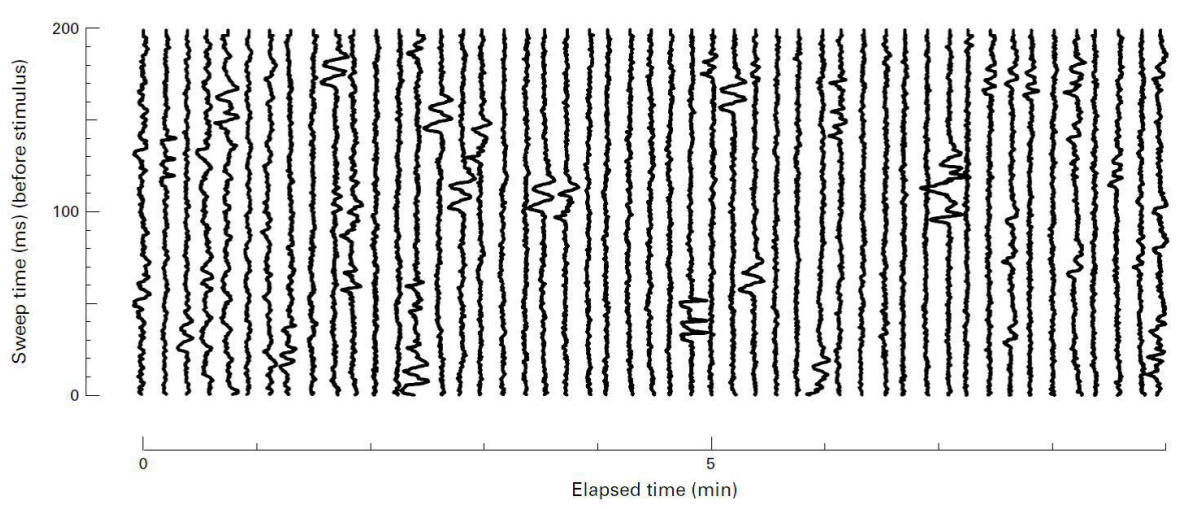

Figure 1 A raster display of the ectopic activity typical of Isaac's syndrome, with uniplet, doublet and multiplet discharges recorded at rest. Adapted from Kiernan et al, 2001. ${ }^{11}$

neuromyotonia patients, ${ }^{13}$ although both a proximal and distal origin of discharges have been recorded. ${ }^{14}$

Although vast improvements in treatment and care have been made since Isaacs' report 60 years ago, Isaacs syndrome remains under-recognised, with diagnostic delays, unaddressed symptoms and poor treatment efficacy for some patients. While largely effective, modern day treatments including membrane stabilising drugs typically encountered in epilepsy, as well as immunomodulatory therapies such as plasma exchange and intravenous immunoglobulin, are not effective in all patients. ${ }^{3}$ We need large-scale, multicentre studies to understand the complex symptom profile and identify novel treatments for refractory patients. Ultimately, further delineation of the complex phenotypes associated with Isaacs syndrome, understanding of specific autoantibody targets and clarification of the association with cancer will be required to facilitate the development of targeted therapies. These advances will provide the key to streamlining diagnosis, treatment and care for patients with Isaacs syndrome in the next 60 years.

\section{Twitter Matthew C Kiernan @jnnp_bmj}

Funding The authors have not declared a specific grant for this research from any funding agency in the public, commercial or not-for-profit sectors.

Competing interests None declared.

Patient consent for publication Not required.

Provenance and peer review Commissioned; internally peer reviewed.

Data availability statement No data are available.

(C) Author(s) (or their employer(s)) 2020. No commercial re-use. See rights and permissions. Published by BMJ.

\section{A) Check for updates}

To cite Park SB, Thurbon R, Kiernan MC. J Neurol Neurosurg Psychiatry 2020;91:1243-1244.

Received 22 July 2020

Accepted 5 August 2020

Published Online First 2 September 2020

J Neurol Neurosurg Psychiatry 2020;91:1243-1244. doi:10.1136/jnnp-2020-324675

\section{REFERENCES}

1 Isaacs H. A syndrome of continuous musclefibre activity. I Neurol Neurosurg Psychiatry 1961;24:319-25.

2 Sinha S, Newsom-Davis J, Mills K. Autoimmune aetiology for acquired neuromyotonia (Isaacs' syndrome). Lancet 1991;338:75-7.

3 Vincent A, Pettingill P, Pettingill R, et al. Association of leucine-rich glioma inactivated protein 1 , contactinassociated protein 2 , and contactin 2 antibodies with clinical features and patient-reported pain in acquired neuromyotonia. JAMA Neurol 2018;75:1519-27.

4 Hart IK, Maddison P, Newsom-Davis J, et al. Phenotypic variants of autoimmune peripheral nerve hyperexcitability. Brain 2002;125:1887-95.

5 Irani SR, Alexander S, Waters P, et al. Antibodies to Kv1 potassium channel-complex proteins leucinerich, glioma inactivated 1 protein and contactinassociated protein-2 in limbic encephalitis, Morvan's syndrome and acquired neuromyotonia. Brain 2010;133:2734-48

6 Lai M, Huijbers MGM, Lancaster E, et al. Investigation of LGI1 as the antigen in limbic encephalitis previously attributed to potassium channels: a case series. Lancet Neurol 2010;9:776-85.

7 Binks SNM, Klein CJ, Waters P, et al. Lgi1, Caspr2 and related antibodies: a molecular evolution of the phenotypes. J Neurol Neurosurg Psychiatry 2018;89:526-34.

8 Park SB, Lin CS-Y, Krishnan AV, et al. Axonal dysfunction with voltage gated potassium channel complex antibodies. Exp Neurol 2014:261:337-42.

9 Gadoth A, Pittock SJ, Dubey D, et al. Expanded phenotypes and outcomes among 256 LGI1/CASPR2IgG-positive patients. Ann Neurol 2017;82:79-92.

10 Boyko M, Au KLK, Casault C, et al. Systematic review of the clinical spectrum of Caspr2 antibody syndrome. J Neurol 2020;267:1137-46.

11 Kiernan MC, Hart IK, Bostock H. Excitability properties of motor axons in patients with spontaneous motor unit activity. I Neurol Neurosurg Psychiatry 2001;70:56-64

12 Noto Y-I, Simon NG, Selby A, et al. Ectopic impulse generation in peripheral nerve hyperexcitability syndromes and amyotrophic lateral sclerosis. Clin Neurophysiol 2018;129:974-80.

13 Vucic S, Cheah BC, Yiannikas C, et al. Corticomotoneuronal function and hyperexcitability in acquired neuromyotonia. Brain 2010;133:2727-33.

14 Santos MO, Swash M, de Carvalho M. The generator site in acquired autoimmune neuromyotonia. Clin Neurophysiol 2017;128:643-6. 